\title{
Best Practices for Students with Learning Disability in Inclusive Schools from the US and UK: Theoretical Analysis and Application to Saudi Arabia
}

\author{
إعداد
}

Hana Ali B Alruwaili 


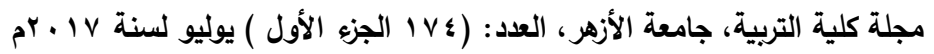

Best Practices for Students with Learning Disability in Inclusive Schools from the US and UK:

Theoretical Analysis and Application to Saudi Arabia

Abstract:

The gap between the children with learning disability and those who are nondisabled especially in the urban districts but the federal has stood in the gap with the rule of law to ensure there is equity and equality among the children with varying abilities in learning. The laws therefore direct that all children are exposed to the same standard-based instructions and curriculum. According to the research, $60 \%$ of children with the learning disability tend to improve their learning ability when they are exposed to the same environment with the nondisabled peers. It also become easier for the instructors to identify the strength and talents in this category of children because disability to learn is not the inability and therefore they also have their strong areas which if given the required attention, they can be a turning point of their lives. In America, 56 public schools were sampled from Miami-Dade County to develop an evaluation tool so that the administrators can make recommendations and a follow up made to confirm the implementation of the inclusive curriculum.

In this research, it will be demonstrated how social healthy it is to train children together without discriminations based on the varying ability to learn. It is also found out that there is a great need for the teachers, administrators and the district to join hands and make professional developments by supporting each other. This will help in development of the inclusivity from lower schools to university level. It is admirable because the children who have the normal learning ability will also benefit from the inclusive curriculum because as they interact with the peers with varying learning ability, they grow socially together by appreciating the variety in nature.

\section{Introduction:}

There is an increasing consensus all worldwide in line with the rights of children that every child has the right to be inclusively educated. For few last years it has been evident that most key international statements have been affirming inclusive education principle and the necessity of working towards ensure that schools are for all- institutions and they appreciate and celebrate everyone equally, facilitate learning, include everybody respond to meet individuals' needs. 


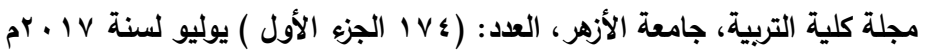

According to the UN laws and regulations on the equity and even distribution of opportunities among people with special needs 1993, the Organization's Conventions on The child's rights 1989 and the UNESCO's statement and framework for action are some of the powerful tools that have struggled to abolish segregated education which have denied children with disabilities the right to mainstream education in addition to reinforcing society's discrimination and prejudices against them. The mentioned documents provide a strong case for inclusion, an aspect that makes inclusive education to be firmly on the national governments agenda.

The UK and the US formally supports the aforementioned documents. For instance in 1994, UK was one of the 92 nations that endorsed the Salamanca statement as well as ratifying the Organization's Conventions on The child's rights in 1991. Drawing from the fundamental human rights perspective, children with disabilities should not be excluded from ordinary communities and institutions in addition to being segregated on the grounds of their disability.

This project will theoretically examine the best practices for students with learning disability in inclusive schools in US and UK and application of the same to Saudi Arabia.

\section{Theoretical framework on learning disability:}

Neurologically, LD is as a result of some heterogeneous disabilities in development of brains that is also contributed by other nonspecific factors of growing awareness. In some children, there are symptoms for these disorders at an early stage before they are at the age of going to school. These symptoms include slow lingual mastery, being dull and low ability to memorize events chronologically. On the other hand there are children who are very active, with good lingual mastery but they take too long to grasp academic concepts. More so, not all dull children have the learning disability (Kagan, 1994). This variation and overlap in the visible symptoms of learning disorder, leaves educators and researchers in a total dilemma. They wonder if learning disabilities can be seen like the physical disability in a child's behavior because there is no existence of a link between the physical appearance and the brain work in most cases.

It therefore means that there are no factors that can be pinpointed to be causes of learning disabilities because even among those who can learn, there is a learning difference. Any factor stated as far as Learning disability is concerned is either a misconception or a negative stereotype. This is mainly because people do confuse learning disability, learning difficulty and learning disorder and use these terms interchangeably. Learning 
disorder is centralized in the academic environment where one gets it hard to learn a concept in the academic field like language, reading, mathematics and speech skills but this does not serve as the only indicator for diagnosis of the same problem. Learning disability is officially diagnosed in the clinic by the professional specialists like the psychologists and the pediatricians although they say there are unknown factors that lead to the failure of the brains of such people to receive and process information and if they do, they do very little and slowly. They cannot finish a task that involves rigorous thinking on their own. During learning, a special way has to be used to enable them get things (Ainscow, 1999).

The problems caused by learning disability do make someone's life ruined and unpleasant throughout their lifespan if interventions are not taken by use of the modern technology. Such interventions vary some being too complex and expensive but the cheapest and the simplest is the instructors' support in classroom. With the support from parents and psychologists, a positive impact can be made on the people with learning disabilities.

The term "disability" is conceptualized in varying ways in different European countries like some take as mental impairment and others take the pupils who have this weakness as those with mental development disorder, some consider it a psychological problem, conduct disorder or generally a learning disorder or impairment.

Inclusive curriculum has been assumed be the better approach to helping children who have this nature than the medical way of seeking the solution to this. The inclusive curriculum is more participative unlike the medical way where the physicians tend to dominate the process and it is not educational and it makes the disability to have a negative impact on the education. The former believes that being disabled is being unhealthy are gradually being dropped and the disabled are gradually no more being considered a different group of people. The biggest challenge is to convince the minds of people to absorb this philosophy and full implement it that a disabled person is healthy and a nondisabled person can be ill (Kagan, 1994).

The participative method through inclusive curriculum does not have a procedure of diagnosis but the learning disability is believed by scholars that it is a disability that is contextual. With the learning disability being contextual, it means that a student might fail to learn in one educational system but have the ability to learn in another system. What makes the student learn in the other system is the presence of an intervention to their disability to learn which a specific educational need (SEN) is. This 
fully relies on the where the personal characters of the students are confronted and the environment in which the learning and teaching would be taking place. The aim of the education has to be having the same impact on the students. This therefore calls for equal treatment but when a SEN is identified, special attention has to be given in order to achieve the ultimate goal of having equal learning outcome on all of them in spite of the existence of the hindrances (Ainscow, 1999).

Among the European countries, United Kingdom has made bigger steps in reducing the gap between the children with learning disability and those who do not have the disability basically by running a comprehensively inclusive curriculum. The federal laws made a good intervention that has caused a commendable attitude change towards the disabilities in the recent past.

Aims of the project:

- To theoretically analyze policies of inclusive schools in US and UK and apply the same in the educational system of Saudi Arabia

- Theoretically analyze teaching of students with disabilities in US and UK and compare the same with the practices in Saudi Arabia.

- To finger point the specific causes of the learning disabilities and if the inclusive curriculum is better than the medical attention to this group.

- Find the different perceptions that different countries have on the pupils with learning disabilities.

\section{The significance:}

The research is of significance in improving teaching of students with learning disability in Saudi Arabia in line with recommended international/ UN standards adapted by countries such as US and UK. Additionally, the work is of significance as no research has been done on comparative educational policies in UK, US and Saudi Arabia. The findings are further of significance as they are likely to provide information that may assist Saudi Arabia teachers and policy makers to adapt best practices for children with learning disabilities. Additionally, the study may assist Saudi Arabia minister for education to serve the identified population; children with learning disabilities.

\section{Research questions:}




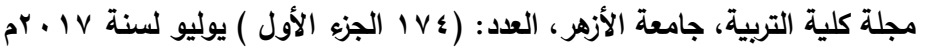

- What are the policies of inclusive schools in UK and US?

- To what extent has US and UK adhered to UNESCO and UN standards on inclusive education policies.

- What are the educational policies for children with learning disabilities in Saudi Arabia?

- To what extent has Saudi Arabia adhered to UNESCO and UN standards on inclusive education policies?

- What are the teaching practices for students with learning disability in US, UK and Saudi Arabia?

\section{Literature review:}

\section{Definition of learning disability:}

Learning disabilities is defined as learning problems as a result of difficulty in cognitive processing in which the dysfunction affects either one or more cognitive processes of an individual, but does not obstruct the overall intellectual ability. The mentioned types of disabilities are characterized by inconsistency between their actual performance and their measured potential on given academic tasks.

Learning disabilities results into creation of gaps between the true capacity of a person and her or his daily performance. However, appropriate intervention, early diagnosis as well as critical components for identifying people with learning disabilities. But with early detection as well as intervention, learning disabilities can cause not only complete loss of self-esteem but also substance abuse, juvenile delinquency, school drop-out, and illiteracy.

\section{Reviews of previous studies:}

Proponents of the inclusive schools hold the belief that students with learning disabilities should be retained and emphasized in mainstream classrooms. This is because by so doing is likely to highlight their disabilities in addition to violating their rights and disrupting their education (Ainscow, 1999). In certain jurisdictions, studies have not succeeded to illustrate that shifting to special school or class makes significant effects on the affected students. According to Au \& Hui (2003), Inclusion students in units which cover special learning and are closely related to mainstreaming of the schooling system or those students who may have been drawn to personal assistance may fail to be perceived to real inclusive. The mentioned are able to make the learners with 


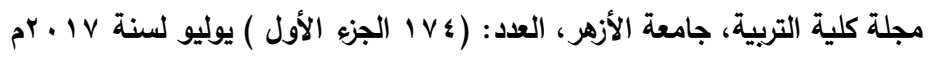

learning disabilities to be isolated an aspect that is likely to perpetuate ongoing segregation forms.

According to Bender (2002) the rights perspective invalidates the argument that the needs of children can be best catered for in any kind of special setting. CAST (2013) indicates to us that the isolation of schools for special needs entails fewer students with special needs. In some schools in UK, approximately 40 percent of the schools population is reported to have some form of additional or special need. However, Dyson \& Ainscow (2003) point out the weight of discussion need to be within the mainstream as well as its capacity to address the student's needs.

Consequently, international policies supporting inclusion schools for children with learning disabilities is driven by human rights and moral imperatives, nonetheless it's therefore essential to gather a confirmatory consideration to confirm the purpose and effectiveness of the education system that is inclusive. Kagan (1994) points out that it's essential to distinguish the matters concerning values or/and rights based on the relative effectiveness aspect of the distinct ways of approach to education. Even though the two are essential, the issue concern on efficacy is one of the primary evidence whereby all the aspects are subject to measurable dimensions.

According to Mercer \& Mercer (2001), researching on the practices that are inclusive is faced with numerous setbacks without an operational educational system that is inclusive as well as methodological difficulties regarding to non-comparability of the students sampled to receive distinct forms of education in different varying educational circumstances. Additionally, inconsistency across various studies leads to comparison challenging. For this reason therefore a good number of scholars have concluded by saying that studies regarding inclusive education has got validity that is limited (Kagan, 1994). However, despite the aforementioned challenges, many reviews have been made on this matter.

Farrell (1997), in his study pointed out few things to control beneficial effects of inclusive educational system on academic and social results of the learners who have the challenges in learning. In the same way, in reviewing about 20 studies, Fuchs \& Fuchs (1994) found both social and academic benefits linked with special education. Another longitudinal study in US that tracked approximately eight thousands $(\mathbf{8 0 0 0})$ of people aged below 30 years indicated that school going young people with learning challenges who are in educational mainstreaming, 40 percent are likely to be employed immediately after leaving school compared to their counterparts who are segregated schooling 
(Kagan, 1994). However, the studies evidence is not totally unreliable: a review of about eight programs used as models were impressive. Other reviews conducted during 1990s did not provide sufficient evidence to prove superiority of inclusive education.

Nonetheless, in several studies, positive effects of inclusive education among studies with learning disabilities have been reported. A study in US based on learners with learning challenges in comparison to a model referred to as "pull out" used in support with inclusive education; discovered that inclusion groupings do a better job in a number of academic measures (Kershner, 2003). The mentioned successful model entailed teacher's planning and collaboration.

On the other hand studies have however indicated that learning disabled or nondisabled students, teachings that are inclusive have been linked to higher levels of academic performance. Lenz, Deshler, \& Kissam (2004) in their studies highlight the importance of ensuring that students become effective leaders in a society that is intellectual in nature. Hence, it is essential for the provided education to ensure chances for interacting with learners who have different characteristics and abilities. The variety and mixture of characteristics which is portrayed in the inclusive classroom provide challenge and stimulus to deep thinking that do not dominate segregated classes.

\section{Situation in UK and US:}

The concept of integration and mainstreaming mainly focused on educational policy. Steps taken towards an educational system that is inclusive were impacted upon by the Salamanca's words said in 1994, which gave directives for all children's needs to be given equal attention. Moreover, as a result of international trend towards inclusive education, in 1997 UK began to start to include students with special needs in the mainstream education. Both US and UK have a key limitation for educators in inclusive education is to realize the most appropriate way to better learners with distinct needs for each one of them in independently. The two countries have adapted two key instructional strategies. One of them is use of cooperative learning while the second one is teaching of learning strategies.

Additionally, in the 1970s, the United Kingdom and the United States provided policies that stated that students with disabilities too have human rights just like other children to access general educational settings. For instance in US, in 1975 the Public Law 94-142 became applicable, additionally, mainstream rules allowed learning disabled students to attend a larger portion of their learning inclusively with other children who are not 


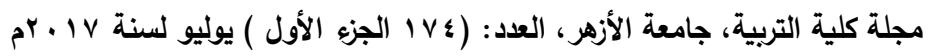

disabled (Putnam, 1998). In 1981, in UK, the Education Act became the law and hence it accepted the integration concept according to Warnock Report (1978). An integration that is functional was suggested in the mentioned report which was in a way the same as that of US's mainstream approach, and disabled students were allowed to join normal classes in either on wholly or partially modes, so that through this, they are encouraged to take part in the activities that take place in school (Tomlinson, 2001).

\section{Situation in Saudi Arabia:}

Saudi Arabia is a country that is growing fast and follows the international community standards in their aim to reform their education system. For instance, the emirates children enjoy free public education and health care via the universality level. Additionally, there is no discrimination of persons with disability in education and the Saudi Arabia government supports inclusion education.

However, up today, there is no study or research regarding children with disabilities in Saudi Arabia in comparison with US and UK. In other words, there have been no comparative or systematic study that analyses the issue of inclusive education for children with learning disabilities in Saudi Arabia in comparison with UK and US (Tomlinson, 2001). Furthermore, in the fields of learning disabilities, specifically in Saudi Arabia, available information entail descriptive data which only records the number of students, programs and teachers but no comparison with other nations on inclusive schools for children with learning disabilities.

The Saudi Arabia has emphasized on the public education that ensures that all students are capable of affording opportunity for maximum growth and hence students with special needs are allowed to attend public schools. Nonetheless, the failure of the schools not only to identify and serve but also meet the students' needs has been an indictment in Saudi Arabia's society and a problem that need to be addressed (Walther-Thomas, Korinek, McLaughlin, \& Williams, 2000).

According to Tomlinson (2001), in the 1990s, the teacher preparation program in Saudi Arabia was launched. Nonetheless, due to lack of research as well as understanding of the commencement of the aforementioned programs and lack of government support in Saudi Arabia made it challenging for teachers to easily identify students with learning disabilities. 


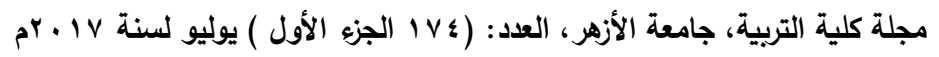

\section{Research method:}

Analytical method will be used for the research whereby there will be theoretical comparison of the educational policies and practices adapted for students with learning disabilities. This analysis will include an analysis of $U K$ and US education policy and initiatives toward students with learning disability in terms of inclusive schools within the theoretical frameworks. Additionally, there will be a comparison of the special education policies in UK and US with other countries in order to adapt the best strategies.

\section{Organization of the Study:}

The study will be divided into five chapters. Chapter one entails introduction to the research study which is the aim of the research, the rationale, the research questions, the rationale and the significance. Chapter two of the research will provide a comprehensive literature review and research related to inclusive education for students with learning disabilities drawing from US, UK and Saudi Arabia. Chapter three of the project will provide information on the method that will be used to conduct the study and it will entail research design, research questions, procedures and data analysis. Chapter four of study will present the results as well as interpretation of data analysis and application of the same. Chapter five will entail findings and provide summary in addition to key conclusions, implications as well recommendations for further studies.

\section{Research limitations:}

The research is prone to not getting the true picture of the world's view of the children and people who have the LD. Basing on the UK and the US alone will only show Saudi Arabia the positive side of the point of view. If we could have considered looking at the developing countries, Saudi Arabia will get the reason to appreciate the steps it has made towards changing the attitude towards the children who have the $\mathrm{LD}$.

The existing attitude towards the children with LD except in US and in UK, it is difficult to carry out a research on this because parents hide their children who have the DL and finding the information about them becomes hard and those few who give the information do not do it comfortably. Therefore, the data and information given here in this study is below the exact level of information that is the actual state of the LD.

\section{Results and analysis:}

Generally, the learning disability is caused by numerous disorders as far as the human body system is concerned. Summing 


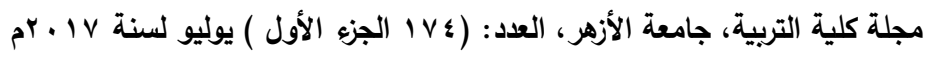

up all the disorders that are believed to have resulted in to DL, the following percentages are arrived at.

\begin{tabular}{|c|c|c|}
\hline Country & Year & Percentage of people with DL \\
\hline United States & 2014 & 12.9 \\
\hline United Kingdom & 2014 & 10.9 \\
\hline Saudi Arabia & 2014 & 13.4 \\
\hline
\end{tabular}
schools with DL

From the statistics, Saudi Arabia has the highest percentage of the people with DL as at the year 2014 school enrolments.

\section{Conclusion:}

The $L D$ is not a permanent state that people have to worry about. There are ways that can make people who have this state to learn and the most efficient one is the participative one by having an inclusive curriculum in schools.

\section{Recommendation:}

The attitude towards children with DL has to totally change and let them be exposed to the similar treatment as those given to other children then SEN has to be identified so that a similar educational impact is made on them. It is clear that there are no specific factors that lead to a child to have the learning disabilities but there are corrective mechanisms to this challenge (Tomlinson, 2001).

The symptoms and characteristics of children with learning disorder do vary among them causing confusion among the specialists on what exactly is the indicator of learning disability. This is a big gap in this field for researchers to feel with endings. Once these causes and symptoms are clearly identified and shown, it will be a clearly paved way for a reliable and efficient way of solving this challenge (Tomlinson, 2001).

The battle against the negative attitude towards children with learning disability is not easy and therefore cannot be fought single handedly. Therefore, taking UK as a role model in this war followed by US; other countries in the world have to borrow a leaf from them. The education systems should be with room for other fields besides academics so that with the variety of activities, the strength of a child can easily be identified (Kershner, 2003). 


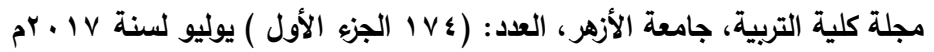

\section{References:}

Ainscow, M. (1999). Understanding the development of inclusive schools. London: Falmer Press.

Ainscow, M. (1997) Towards Inclusive Schooling, British Journal of Special Education, 24(1), 3-6.

Au, M. L., \& Hui, L. H. (2003). Inclusion or integration for Hong Kong? In M. H. H. Leng, C. R. Dowson \& M. G. Moont (Eds.), Inclusive education in the new millennium (pp. 4957). Hong Kong: Association for Childhood Education International-Hong Kong \& Macau and Education Convergence.

Bender, W. N. (2002). Differentiating instruction for students with learning disabilities: Best practices for general and special educators. Thousand Oaks, CA: Corwin Press.

CAST. Summary of universal design for learning concepts. Retrieved September 20, 2004, from: http://www.cast. org/ udl/ index.cfm? $i=7$

Dyson, A. and Ainscow, M. (2003). Standards and inclusive education: schools squaring the circle, unpublished paper. University of Manchester,Faculty of Education.

Kagan, S. (1994). Cooperative learning. San Clemente, CA: Kagan.

Mercer, C. D., \& Mercer, A. R. (2001). Teaching students with learning problems. Upper Saddle River, N.J.: Merrill/Prentice Hall.

Farrell, P. (1997). Teaching Pupils with Learning Difficulties: Strategies and Solutions. London: Cassell.

Fuchs D., \& Fuchs L. S. (1994). Inclusive schools movement and radicalization of special education reform. Exceptional Children, 60(4),294-309.

Kershner, R. (2003). Teaching strategies and approaches for pupils with special educational needs. Unpublished briefing paper, University of Cambridge.

Lenz, B. K., Deshler, D. D., \& Kissam, B. R. (2004). Teaching content to all: Evidence-based inclusive practices in middle and secondary schools. Boston, MA: Pearson Education. 
Putnam, J. W. (1998). The process of cooperative learning. In J. W. Putnam (Ed.), Cooperative learning and strategies for inclusion: Celebrating diversity in the classroom (pp. 17-47). Baltimore: Paul H. Brookes.

Tomlinson, C. A. (2001). How to differentiate instruction in mixed ability classrooms (2nd ed.). Alexandria, VA: Association for Supervision and Curriculum Development.

Walther-Thomas, C., Korinek, L., McLaughlin, V. L., \& Williams, B. (2000). Collaboration for inclusive education: Developing successful programs. Boston: Allyn \& Bacon. 